\title{
Encoding and Decoding Photoperiod in the Mammalian Pars Tuberalis
}

\author{
Sandrine M. Dupré \\ University of Manchester, Faculty of Life Sciences, Manchester, UK
}

\section{Key Words}

Photoperiodism • Melatonin - MT1 • Pars tuberalis •

Prolactin

\begin{abstract}
In mammals, the nocturnal melatonin signal is well established as a key hormonal indicator of seasonal changes in day-length, providing the brain with an internal representation of the external photoperiod. The pars tuberalis (PT) of the pituitary gland is the major site of expression of the $\mathrm{G}$ coupled receptor MT1 in the brain and is considered as the main site of integration of the photoperiodic melatonin signal. Recent studies have revealed how the photoperiodic melatonin signal is encoded and conveyed by the PT to the brain and the pituitary, but much remains to be resolved. The development of new animal models and techniques such as cDNA arrays or high throughput sequencing has recently shed the light onto the regulatory networks that might be involved. This review considers the current understanding of the mechanisms driving photoperiodism in the mammalian PT with a particular focus on the seasonal prolactin secretion.
\end{abstract}

Copyright $\odot 2011$ S. Karger AG, Basel

\section{Introduction}

Animals living in seasonal environments are faced with predictable environmental challenges of cycles of food availability and climatic variability, which require

\section{KARGER}

Fax +4161306 1234 E-Mail karger@karger.ch www.karger.com

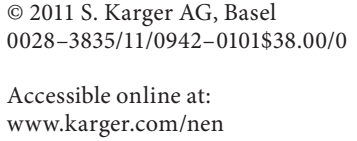

that they adjust their physiology over the year in order to survive. As a consequence, seasons of birth are tightly constrained to the optimal time of year, and annual fattening, metabolism and cycles of growth are generally matched to annual changes in food availability. Such physiological processes require long-term predictive changes in neuroendocrine circuits. For instance, reactivation of the reproductive system is a process that takes weeks to months, and the timing of conception also needs to be adjusted to ensure birth patterns are matched to the optimal season, when environmental conditions are the most favourable to raise the offspring. Therefore, tracking but also anticipating changes in day length are important features of photoperiodic time measurement. Various models, including the external and the internal coincidence models (reviewed in [1,2]), have been proposed to describe photoperiodic time measurement mechanisms. In the external coincidence model, light entrains the photoperiodic response and triggers seasonal responses only when present during a particular window of time (or photo-inductive phase). The internal coincidence model on the other hand infers the existence of two oscillators both entrained by light, tracking dawn and dusk; in this model photoperiod is represented by the interval between these two oscillators. Current knowledge on photoperiodic time measurement in mammals cannot rule out either of these models suggesting they are nonexclusive.

Photoperiodic responses were first observed in insects and birds in the 1920s and about a decade later in mam- 


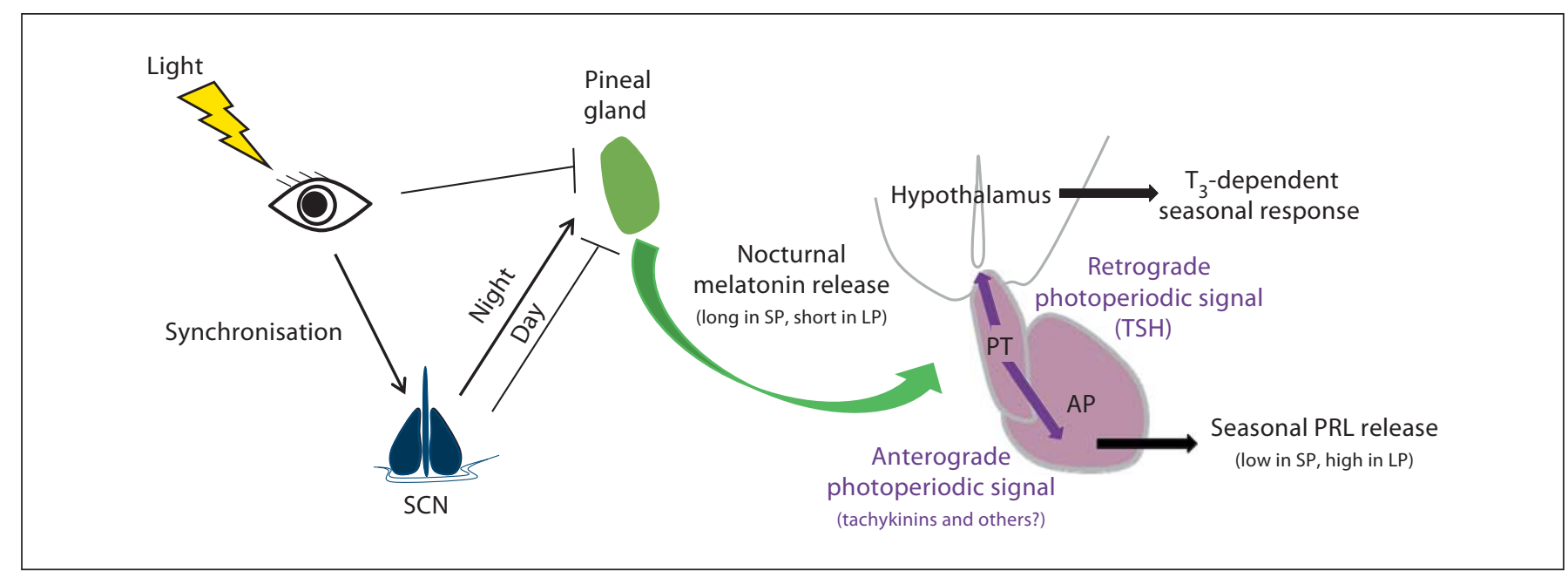

Fig. 1. Seasonal regulation of prolactin in mammals. In this simplified cartoon, light signalling through the eyes inhibits the activity of the pineal gland and resets the circadian activity of the SCN which in turn controls the activity of the pineal gland. This leads to an exclusive nocturnal secretion of melatonin which duration signal (short in LP and long in SP) is read by the PT. The photoperiodic information is then conveyed to the AP to control the seasonal production and release of PRL. The PT is also known to convey retrograde photoperiodic signals towards the hypothalamic third ventricle to control $\mathrm{T}_{3}$-dependent photoperiodic reproductive responses [104]. mals (reviewed in [1]). These responses can vary among species and include, among others, seasonal regulation of reproduction, thermoregulation, hibernation, migration behaviour, fattening and metabolic cycles and pelage growth and development. Mechanisms underlying mammalian seasonal physiology are complex and diverse with different species using seasonal timing to their own advantage. This is exemplified by the distinction between photoperiodic and circannual species (reviewed in $[3,4]$ ). In the later, an internal circannual timer allows the animals to successively go through periods of quiescent and active reproductive activity when exposed to regular photoperiodic conditions. On the other hand, short lived species do not need such a long term mechanism, they respond quickly to the external photoperiod which in turn resets their physiology. Photoperiodic species have the ability to revert to an active reproductive state when exposed for a long duration to short photoperiod (SP), a process called refractoriness and reviewed in Morgan et al. [5] .

In mammals, the nocturnal secretion from the pineal gland of the hormone melatonin is tightly regulated by the external light-dark cycle. Melatonin provides the brain with an internal endocrine representation of the external photoperiod, accurately tracking seasonal changes in night length. This hormone of darkness is a major internal cue which acts on neuroendocrine circuits and its function in regulating seasonal physiology and seasonal breeding has been extensively studied (reviewed in [6]). The description of sites of action of melatonin in the brain in the 1990s lead to the identification of a little studied proximal region of the pituitary gland, the pars tuberalis (PT) (reviewed in [7]). We now know that the $\mathrm{PT}$ is a major site of action of melatonin for the regulation of mammalian seasonal physiology $[7,8]$. This review focuses on the role of the photoperiodic processes driven by melatonin with a particular emphasis on the seasonal regulation of prolactin (PRL) secretion (fig. 1).

\section{Melatonin, an Endocrine Index for Day Length}

\section{Melatonin Synthesis and Mode of Action}

The main source of circulating melatonin (5-methoxy $\mathrm{N}$-acetyltryptamine) is the pineal gland, specialised to metabolise indoleamines from the essential amino-acid tryptophan. The uptake of tryptophan in pinealocytes leads to the formation of melatonin through a 4-step metabolic pathway involving arylalkylamine- $\mathrm{N}$-acetyltransferase (AA-NAT) and N-acetylserotonin O-methyltransferase (ASMT, also known as HIOMT). AA-NAT activity is inhibited by direct light input from the retino-hypothalamic tract and regulated by the circadian control of the suprachiasmatic nuclei (SCN) via sympathetic outflow and controls the timing of melatonin production, 
while ASMT controls the absolute levels of melatonin produced during the night. Melatonin production is therefore under tight regulation, and its release at night, in both nocturnal and diurnal species, provides an indication of the time of the day to the different organs/tissues in the body, including the SCN (reviewed in [9]) (fig. 1). With a secretion pattern inverse to the duration of the light phase, melatonin also provides a good endocrine index of the external photoperiod [1] with long or short duration signals in SP or long photoperiods (LP), respectively, and has a major role in regulating seasonal physiology (reviewed in $[6,10])$. The release of melatonin in the bloodstream and the cerebro-spinal fluid (CSF) [11], and its lipophilic nature are responsible for the pleiotropic effects of melatonin in diverse areas of the brain and peripheral tissues [12].

Three melatonin receptors have been identified: MT1, MT2 and Mel1c, all belonging to the GPCR family. MT1 and MT2 are both found in vertebrates although MT2 isn't functional in some species [13]. Mellc is found in chicken, fish and xenopus only [14]. GPR50, an orphan GPCR has recently been characterised as the mammalian ortholog of Mel1c [15].

\section{Melatonin and Photoperiodism}

The importance of melatonin in the seasonal regulation of animal physiology and behaviour has been extensively reviewed $[6,16,17]$. The role of melatonin as a neuroendocrine timing signal was first defined in experiments which involved pinealectomy and timed melatonin replacement in hamsters and sheep (reviewed in [1]), showing that the duration of the melatonin signal is a photoperiodic cue, with long duration signal providing a SP-like response (reviewed in [18]). Studies involving targeted administration of melatonin in diverse areas of the brain determined that these effects were through a region within or surrounding the hypothalamus; however, the exact target of melatonin in the brain responsible for its seasonal effect was first unravelled with the description of a peculiar pattern in melatonin binding sites. 2 -[ $\left.{ }^{125} \mathrm{I}\right]$ iodomelatonin binding sites were characterised in the SCN, supporting the role of melatonin in resetting the circadian clock and other regions of the hypothalamus. However, the binding observed in these areas was much lower than that observed in a discrete region of the pituitary: the PT (reviewed in [7]). The cloning of melatonin receptors (described above) confirmed the confined expression of MT1 within the PT in mammals, suggesting the central role for the PT in relaying the melatonin photoperiodic signal.

PT and Photoperiodism in Mammals

\section{PT, a Melatonin Target Tissue to Control Photoperiodic Responses}

The PT takes its origin from the lateral lobes of the Rathke's pouch to form a distinct region from the $\mathrm{PD}$ and PI [19]. Many lines of evidences support now the concept that the PT is an entity of its own from a developmental, structural and functional point of view.

\section{Development and Ultrastructure of the PT}

Ultrastructural studies during development in rodents provided important insights in the now well-described characteristics of the PT such as the presence of glycogenlike particles, secretory cells and an early differentiation during neonatal life [20]. The formation of the PT has recently been shown to involve the bHLH transcription factor Hes1 (hairy enhancer of split), indeed the anterior pituitary of $\mathrm{Hes}^{-1-}$ mice is only represented by the PD with the PT failing to develop from the primordium [21]. Moreover, the pituitary specific transcription factor, Pit-1, is not expressed in the PT-specific cells [22-24]. These data clearly demonstrate that the PT and PD are two distinct tissues early on during their ontogeny. During embryonic development, the PT already shows most of its adult cytological features at the time that the PD starts to show signs of secretory activity, and reaches its final cellular organisation around birth. This precocious secretory differentiation was described as a 'striking feature' of the PT [20] and the description of the PT as the most vascularised region of the pituitary already suggested at the time an important functional role for the PT.

In all species studied, three PT cells types have been distinguished: follicular cells, PT-specific secretory cells and PD-like cells (the later originating from the PD and found in the zona tuberalis) (see review in Wittkowski et al. [27]). Recent studies in the rat have characterised up to five different secretory cell types [25]. In the same studies, the authors described the follicular cells as cistern-like structures making close contact with the PT-specific cells, portal capillaries and tanycytes; this complex cellular network highly supports a central role for the PT in processing information to and from the brain and periphery. The characterisation of secretory cell types in the PT suggested that this role was of an endocrine type, a hypothesis supported by immuno-histological evidences in many animal species showing the presence of gonadotrophs and thyrothrophs, morphologically different from the PD cells. PT cells express many of the PD hormone subunits with variations among different species [26-29]. $\beta$ TSH and the alpha common subunit ( $\alpha$ GSU) are found

Neuroendocrinology 2011;94:101-112 
at the protein and mRNA levels in PT-specific cells of many species (reviewed in [29-31]), but unlike in the PD, they are not regulated by TRH or thyroid hormones primarily because of the lack of expression of their respective receptors [22].

\section{MT1 Expression and Photoperiodic Response of the PT}

The PT is a dynamic tissue responding to the external photoperiod relayed by melatonin. Ultra structural analyses of the PT have demonstrated a seasonal-dependent change in morphology and secretory activity [32-35]. Similarly, melatonin administration induces SP-like modifications in the PT $[36,37]$. These anatomical modifications associated with changes in photoperiod and melatonin signal duration are paralleled with changes in immuno-reactivity and/or mRNA expression of $\beta$ TSH and $\alpha$ GSU in PT specific cells (in Siberian hamsters [3841], in European hamsters [42, 43], in sheep [29, 44], and in mice [45]).

The specific expression of the melatonin receptor, MT1, is another characteristic feature of the PT. Melatonin binding sites can be characterised in the PT before the development of the hypophyseal-portal system during ontogenesis (reviewed in [30]). MT1 is exclusively found in the adult PT-specific cells and zona tuberalis, in most species studied $[31,46]$. However, during development, MT1 is transiently expressed in gonadotrophs, before the maturation of the GnRH system [47]. Based on this observation, it was proposed, even though the PT matures very quickly, that it might remain undifferentiated, offering greater plasticity and allowing rapid responses and adaptations to different stimuli such as a change in photoperiod (reviewed in [18]).

Studies in rats and hamsters show that MT1 is co-expressed with $\beta$ TSH and $\alpha$ GSU in PT-specific cells while no co-expression has been revealed to $\beta \mathrm{LH}$ or $\beta \mathrm{FSH}$ expressing cells $[24,31,42]$. The above description of the suppression of $M T 1$ expression in the embryonic gonadotrophs was shown to be mediated by the induction of the transcription factor Egr1 [47]. Interestingly, Egr1 was shown to repress $M T 1$ and stimulate $\beta L H$ expression in these cells [47], providing an explanation to the lack of expression $\beta \mathrm{LH}$ in the PT-specific cells which are defined as Pit-1-independent thyrotrophs [24]. MT1 expression is regulated by melatonin in the PT-specific cells [31, 42]. Melatonin can therefore self-regulate its actions by downregulating $\mathrm{MT} 1$ at the mRNA and protein levels leading to a progressive loss of melatonin signalling during the dark phase [48].
First, the early development of the PT combined with the specific expression of MT1 suggests an important role for melatonin during neonatal life [49]. Indeed, a correlation between changes in prenatal photoperiodic exposure and gonadal development or gene expression in the PT have been described [50-54]. Second, the fact that Siberian hamsters, a highly photoperiodic species, do not have a functional MT2 [13] and observations from MT1 and MT2 knock-out mice, clearly emphasises the specific role of MT1 in mediating photoperiodic responses to melatonin [55].

\section{The Seasonal Regulation of PRL Is Driven by PT PRL-Releasing Factor(s)}

Melatonin was shown to regulate reproduction and PRL by targeting the hypothalamus and the PT (reviewed in [56]). Moreover, the seasonal changes in PRL secretion are unlikely to be directly responsible for the seasonal change in reproduction [57], further emphasising this dual site of action for melatonin in regulating photoperiodic physiology. The effect on the hypothalamus to regulate reproduction has been reviewed elsewhere [6], here is summarised the current knowledge on the seasonal regulation of the pituitary hormone PRL (fig. 1).

Rhythmic PRL secretion, with high and low circulating concentrations in the summer (LP) and winter (SP), respectively, is an important feature of seasonal physiology and is observed in both SP and LP breeders (reviewed in [58]). Strong evidence shows that the melatonin duration signal does not target the PD [59] or hypothalamic factors such as dopamine $[60,61]$ to regulate the seasonal PRL rhythm. Indeed the PT is the major tissue target in this process (reviewed in [56, 62]) (fig. 1). The central role of the PT was clearly demonstrated in vivo in sheep, by Lincoln and Clarke [60]. In their studies, they surgically disconnected the pituitary from the hypothalamus via the insertion of an aluminium sheet, abrogating neuronal input from the hypothalamus to the pituitary and leaving intact the pituitary and its blood supply. Alternative exposure to LP and SP of these hypothalamo-pituitary disconnected (HPD) rams lead to a seasonal PRL rhythm associated with seasonal moult. Moreover, melatonin implants in LP-exposed HPD rams suppressed PRL secretion as shown in the sham controls. This is compatible with the hypothesis that melatonin directly regulates the seasonal PRL rhythm at the level of the pituitary without action on hypothalamic circuits (reviewed in [56]).

The identification of factors, termed tuberalin(s) [63, 64], secreted by the PT and responsible for the seasonal stimulatory effect on PRL secretion from the PD has not 
yet been fully determined (reviewed in [30]). Under LP conditions, secretion of many proteins from the ovine PT, ranging from 14 to $100 \mathrm{kDa}$, was enhanced by forskolin, an effect reversed by melatonin [65]. Further purifications of these products lead to the description of very small (as small as $1 \mathrm{kDa}$ ) uncharacterised PRL secretagogues produced in the PT (reviewed in [66]). It is noteworthy that actinomycin D does not affect the secretion of forskolin-stimulated PT-specific proteins, suggesting the involvement of post-translational events [67]. In vitro experiments confirmed that in LP conditions, the PT secretes products which can stimulate PRL secretion from PD cells $[59,64,68]$. Moreover, these experiments have also shown that the response of the PD to this LP signal is also photoperiodic, revealing the existence of a photoperiodic memory within the PD itself $[59,69,70]$.

The nature of PRL-releasing factor(s) driving the photoperiodic response of PRL secretion in seasonal mammals has yet to be established. Free $\alpha \mathrm{GSU}$, known to stimulate PRL $[71,72]$ and shown to be seasonally regulated in the PT, has been considered as a potential candidate but differences in expression observed between sheep and hamsters (upregulated or downregulated protein expression in LP, respectively) do not support its role as tuberalin (reviewed in [30]). However, its implication can still be considered, as its potential dimerization with a PT-specific $\beta$ subunit has not yet been fully investigated. This hypothesis can be supported by the description of a PT-specific secretory product: tuberalin II, characterised from bovine PT extracts and suggested to be a PT-specific $\beta$-glycoprotein [73]. Recently, cDNA array studies have been performed on PT collected from sheep maintained on LP or SP conditions and from these novel candidate PRL-releasing peptides identified. These include substance $\mathrm{P}$ and neurokinin $\mathrm{A}$, members of the tachykinin family, both of which are known regulators of PRL secretion. Both have the correct molecular weight for proposed tuberalins and their expression have previously been characterised in the PT [74]. The expression of the TAC1 gene encoding these peptides is progressively upregulated in the sheep PT following LP exposure [75], which parallels the progressive rise in PRL secretion. Intriguingly, the expression of the neurokinin receptors (NK1,2 and $3 \mathrm{R}$ ) in the sheep PD is not observed in PRL expressing cells (lactotrophs), suggesting the involvement of indirect pathways perhaps via gonadotrophs or folliculo-stellate cells (FCS), as both of them express neurokinin receptors. The recent description of an endocannabinoid system in the PT in mammals showed that non-peptidergic candidate should also be considered [76]. In these studies, the authors described an increased concentration of 2-arachidonoyl glycerol (2-AG) in the PT under LP conditions, and the ability of 2-AG to induce PRL secretion from cultures of PD cells. Here again, the cannabinoid receptor, $\mathrm{CB1}$, is not found in the lactotrophs but mostly in the FCS. The implication of the endocannabinoids system in photoperiodism has been reviewed elsewhere [76]. In both this study and the work described above on tachykinins, intermediate cell types (such as gonadotrophs and FCS) within the PD are likely to be involved in mediating the seasonal PRL regulation. This hypothesis is supported by the description of seasonally regulated paracrine interactions between gonadotrophs and lactotrophs [77] and seasonal secretory activity of FCS [78] which are known to influence PRL secretion [79]. Thus, photoperiodic signalling to the lactotrophs may operate via intermediary pituitary cell types.

\section{Molecular Photoperiodic Code in the PT}

\section{Melatonin Signal Transduction Pathways in the PT}

A number of studies have shown that melatonin acts as a potent regulator of CAMP in the PT. Various in vitro studies using PT dispersed cells or explants revealed that melatonin does not affect basal cAMP concentrations but is however a strong inhibitor of forskolin-induced cAMP accumulation (reviewed in [80]). In the PT, melatonin was shown to inhibit the classic transduction cascades induced by the accumulation of cAMP including PKA activity, CREB phosphorylation and MAPK activity (reviewed in $[66,81])$. This effect is mainly mediated via coupling with a $G \alpha_{i}$ protein; however, pertussis toxin treatment only partially suppresses melatonin effects, suggesting a coupling with other $\mathrm{G} \alpha$ proteins such as $G \alpha_{\mathrm{z}}$ (reviewed in [30, 66]).

The absence of direct effects on the activity of the adenylate cyclase (AC) suggests that melatonin acts indirectly to inhibit the effects of an unknown stimulatory factor, termed 'StimX' [7] (fig. 2). Forskolin is a common tool used to activate $\mathrm{AC}$ and the nature of the endogenous factor responsible for the stimulation of the $\mathrm{AC}$ in the $\mathrm{PT}$ still remains unclear. Many factors such as adenosine have been investigated; however, in most cases melatonin do not inhibit their stimulatory effects on cAMP accumulation in the PT (reviewed in [30]). The nature of 'StimX' has been proposed to be a protein over $10 \mathrm{kDa}$, found in serum composition as inferred by studies in ovine PT primary cultures; there, serum activates cAMP and enhances $\mathrm{Ca}^{2+}$, an effect that was found to be both 


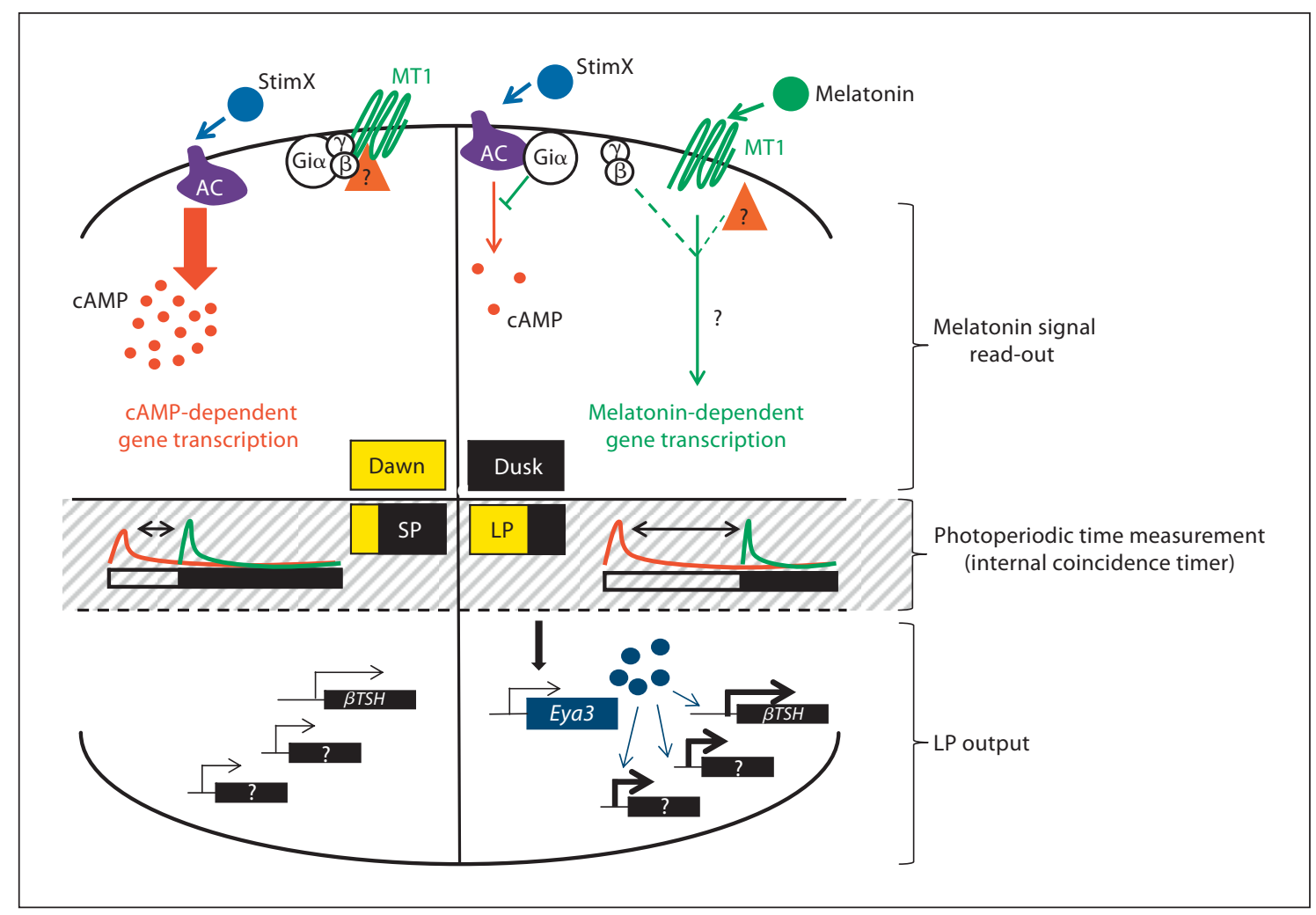

Fig. 2. Integration of the photoperiodic melatonin signal in PTspecific cells. The stimulation of AC by an unknown factor (StimX) [7] leads to an increase of intracellular cAMP responsible for the induction of CAMP-dependent gene transcription at dawn. At the onset of the dark phase, melatonin binds to its receptor MT1 which triggers the release of its coupled $\mathrm{G} \alpha_{\mathrm{i}}$ subunit and the inhibition of AC. As a consequence of MT1 activation, unknown events presumably occurring via cAMP-independent pathways, lead to the transcriptional activation of a subset of genes at dusk. The transcriptional activation of specific set of genes, such as clock genes, at dusk and at dawn provides a local indication of the photoperiod [94]. The expression of Eya3 in LP is thought to be a major switch which drives an LP response among which is the activation of $\beta$ TSH $[75,102,103]$. melatonin and heat sensitive [82]. One possible candidate was considered to be the pituitary adenylate cyclase-activating polypeptide (PACAP), but PACAP receptors have only been characterised in the median eminence and not the PT [83]. Nevertheless, PACAP-dependent cAMP induction is inhibited by melatonin suggesting that PACAP acts on neighbouring cells of the ME to release a factor which is able to stimulate cAMP release in melatonin responsive PT cells.

An important characteristic of melatonin regulation of cAMP in the PT is the sensitisation mechanism observed after prolonged melatonin treatment, leading to an increased AC activity upon melatonin withdrawal (reviewed in [84]). This phenomenon is a strong feature of the PT since it does not occur in every cell type. Indeed, in the PT, sensitisation requires at least $4 \mathrm{~h}$ of exposure to melatonin and is established by $8 \mathrm{~h}$ while in other cell types, such as $\mathrm{CHO}$ cells, sensitisation was shown to occur with as little as $1 \mathrm{~h}$ exposure [85]. The development of the melatonin duration-dependent sensitisation mechanism in the PT does not require protein synthesis, and was shown to involve the coupling with $\mathrm{G}_{\mathrm{i}}$ and a change in Tyrosine phosphorylation of the AC [86, 87].

\section{Molecular Encoding of the Photoperiodic Signal within the PT}

The expression of clock genes in the PT was first demonstrated by the description of the mouse Period gene (Per1) [88]. This discovery was followed by studies in hamsters and sheep where the amplitude and timing of expression of Perl in the PT was shown be dependent on the duration of the melatonin signal (reviewed in [89]). Most clock genes including Clock, Bmal1, Per1, Per2, Cry1 and $\mathrm{Cry} 2$ have now been shown to be expressed in the PT, 
but unlike in the SCN, their expression is not under strict circadian control [90]. In the SCN, the photoperiodic melatonin signal does not affect the phase of expression of clock genes but was shown to have an effect on the amplitude of Per1 and Per2 rhythms. In the PT, however, melatonin is essential for the expression clock genes and controls their relative phasing [91-93]. Melatonin, itself an output of the circadian clock, provides therefore a clock input to the PT [89]. A mechanism has been proposed whereby the duration of the melatonin signal encodes a photoperiodic information within the PT via phasing of clock gene expression and has been proposed to operate as an internal coincidence timer for photoperiodic time measurement (reviewed in [94]) (fig. 2). In this model, Perl expression in the PT peaks at the onset of the light phase while Cryl peaks at the onset of the dark phase, the interval separating the peak of expression of these two genes therefore varies according to the photoperiod. By this means, seasonal response via PER/CRY protein complexes has been proposed.

Perl is an early response gene responding to the rise in cAMP (via CRE elements) in the morning when circulating melatonin concentration declines, de-repressing cAMP accumulation. This induction of Perl at dawn is concomitant to the CAMP-dependent rise of ICER (inducible cyclic AMP response element repressor) which itself acts as a repressor of Per1 expression [95]; Per1 expression profile is therefore characterised by a sharp increase at dawn followed by a quick decline and is a good molecular indicator of the onset of the light phase. The repressive effect of ICER on Perl has been proposed to be responsible for the unexpected differences in amplitude in Perl expression in SP and LP (reviewed in [66]). Indeed, Perl amplitude is found to be suppressed in SP compared to LP in the PT of different species studied [93, $95,96]$, which is counterintuitive since the sensitisation of the AC in SP (described above) would be predicted to lead to higher cAMP accumulation at dawn in SP compared to LP; a paradox that can be explained by the repressive effect of ICER on Perl expression. Interestingly, melatonin was also shown to suppress gene expression via cAMP-independent pathways [48], suppressing in particular the expression of E-box containing genes, including Perl [96]. If melatonin is therefore an inhibitory signal to Perl expression in the PT, it is important to point out that an intact endogenous melatonin rhythm is essential for the expression of Perl in this tissue. Indeed, in the PT of MT1 KO mice or melatonin-deficient C57BL mice, Per1 expression is abolished [46, 81]. Similar observations have been made in pinealectomised hamsters [97] and melatonin injections can rescue Per1 expression, if given after the surgery $[46,90]$. Taken together, these observations on Perl expression show that, in the PT, melatonin acts as a regulator of a complex regulatory network.

In contrast to the activation of dawn-associated genes (i.e. Perl) by a cAMP-mediated mechanism, melatonin is also known to directly activate gene transcription at the onset of darkness. Melatonin-dependent transcriptional activation in the PT was shown in both sheep and melatonin-proficient C3H mice [98-100] with the best studied example being Cryl. This upregulation occurs very quickly at dusk and the pathways involved, presumably involving cAMP independent mechanisms, remain uncharacterised. It was recently shown that the transcription factor Egrl (early growth response 1) contributes to the melatonin-dependent activation of Cryl transcription [99], but whether Egrl contributes to the transcriptional activation of the other melatonin induced genes hasn't yet been determined.

\section{Decoding the Photoperiodic Signal: The Long-Day Response in the PT}

In sheep, the stimulation of the PRL secretion is initiated within $24 \mathrm{~h}$ after a switch from SP to LP and is accompanied by quick changes in clock gene expression [101]. When exposed to prolonged LP, they become refractory with PRL concentration progressively declining from 10 weeks onwards. In such conditions, however, clock gene expression in the PT still exhibits a LP-like pattern (including Rev-erb $\alpha$, Perl, Per2 and Bmal1) [44]. Similar studies in hamsters have revealed that SP refractory and SP control animals express a similar temporal pattern of clock gene expression in the PT [92]. These observations, made in hamsters and sheep, show that the melatonin-dependent clock gene expression is a primary mechanism encoding photoperiodic information in the PT [44]. On the other hand, in LP-refractory sheep, $\beta$ TSH and $\alpha$ GSU retain a SP-like pattern of expression, suggesting that these factors belong to a secondary mechanism, distinct from the internal coincidence read-out and driving the circannual clock (fig. 2). Therefore, the melatonin read-out in the PT de-couples from the neuroendocrine output.

We do not fully understand how the melatonin duration signal, encoded via regulation of clock genes and others, is decoded into photoperiodic output driving seasonal physiology, nor how this is linked to the operation of a circannual clock. Recent studies, using cDNA microarrays in PT from sheep culled after 8 weeks of SP expo- 
sure or after one day of LP exposure, have identified Eya3 as a LP-induced gene, activated immediately after switching to LP exposure [75]. Eya 3 is a transcription factor with multiple functions, the best described being its role in photoreceptor differentiation, suggesting that an ancient photoreceptor developmental pathway may be used in the PT to track the duration of the light/dark phase. Eya3 has recently been characterised as a core component of the LP switch triggering photoperiodic response in sheep and mice $[102,103]$. In these studies, Eya3 was shown to complex with Sixl (Sine oculis homeobox homolog 1) to synergise the Tef (thyrotroph embryonic factor)-dependent activation of $\beta$ TSH in the PT of both species. This finding formally links the described function for TSH with the regulation of the photoperiodic availability of thyroid hormones in the tanycytes, which in turn regulates the $\mathrm{T}_{3}$-dependent activation of the reproductive axis [104]. How Eya 3 expression is regulated in the $\mathrm{PT}$ remains to be investigated, however the described repressive effect of melatonin [102] suggests that, in common with Per1, Eya3 may be downregulated via regulation of circadian E-boxes and upregulated via action on CRE elements (following de-repression of cAMP concentrations). Interestingly, Eya 3 expression is de-repressed $12 \mathrm{~h}$ after the dark onset in both SP and LP, providing strong support for an external coincidence model, where concomitant de-repression and activation signals in LP would lead to a stronger transcriptional activation of Eya3 in LP compared to SP [105]. The identification of Eya3 thus opens the way to further investigation to understand how the LP response is decoded in the PT. For instance, it would be of major interest to identify other Eya3 targets in the PT and investigate whether Eya3 is also involved in the cascade of events leading the seasonal regulation of PRL and other neuroendocrine pathways in the PD (fig. 2).

\section{Perspectives}

The central role of the PT in photoperiodism is clearly established, however much remains unknown regarding the signal encoded and decoded within the PT to translate the melatonin photoperiodic signal. Our current knowledge on melatonin signalling in the PT clearly places intracellular cAMP as a key component integrating different signals (such as StimX and melatonin, see fig. 2). However, recent findings suggest the existence cAMPindependent pathways driven by melatonin important in the transcriptional regulation of many genes. Data so far have demonstrated that the original models proposed for photoperiodic time measurement (i.e. the external and internal coincidence models) are not exclusive. The challenge is now to characterise the pathways triggered by melatonin and decipher their interplay to understand how the daily duration of the melatonin signal in translated into seasonal information within the PT.

\section{Alternative Models to Investigate Mammalian PT \\ Signalling - a Conserved Mechanism}

The advent of molecular techniques to investigate gene regulatory networks has recently contributed to major advances in the field. Although photoperiodic species such hamsters and sheep have so far proven to be the best models, the use of mice or birds offer some advantages since more molecular tools available. Although they are not considered a photoperiodic species, mice have recently been shown to be a useful model to investigate PT signalling in mammals. They retain a photoperiodic-dependent expression of clock genes in the PT mediated by MT1 $[106,107]$ suggesting that the adaptation to photoperiod in animals lies in the output driven by the PT and not in the melatonin read-out. Similarly, birds do not employ melatonin for photoperiodic time measurement [108], and are known to decode the photoperiod signals by direct action of light on deep brain photoreceptors [109-112]. Despite this, clock genes remain under photoperiodic control in the avian PT [113] and the LP response is broadly similar to responses observed in mammals [114].

\section{Modulators of MT1}

As described above, the PT is a highly specialised tissue comprising different cell types, distinctive from the PD cells, and interacting with both the hypothalamus and the pituitary. To date, no cell lines have been recovered from this tissue which can recapitulate the function of the PT in culture. For this reason, PT primary cultures have been mainly used to study melatonin signalling pathways in the PT, and such experiments are slow and technically demanding. There is therefore a general lack of understanding of the function and of MT1 in the PT. Data so far show the complex nature of the melatonin signal in the PT, with both stimulatory and inhibitory effects on gene transcription via cAMP-dependent and independent pathways, strongly suggesting the involvement of yet unidentified factors specific to the PT (fig. 2).

Nuclear receptors have been proposed to play a role in melatonin signalling, with evidence that melatonin can bind members of the ROR/RZR family, some of which are known to be expressed in the PT [115]. Studies in MCF-7 
human breast cancer cells have shown a role for melatonin-dependent transcriptional regulation of $\mathrm{ER}$ and $\operatorname{ROR} \alpha$ [116]. Whether melatonin binds or affects the expression of nuclear receptors or whether it alters their function in the PT has yet to be investigated.

The fine tuning of MT1 signalling can be determined by many factors, including its putative heterodimerisation with other GPCR [117], its interactions with other intracellular proteins [117], its coupling with different heterotrimeric $\mathrm{G}$ proteins or its action on different $\mathrm{AC}$ substrates [87]. Although it is not functional in some seasonal species, MT2 has recently been characterised in the sheep PT, with expression levels lower than those of MT1 [118]. With its ability to form heterodimers with MT1 [117], the involvement of MT2 in melatonin signalling in the PT remains to be investigated. Members of the RGS (regulators of G-protein signalling) family are currently being considered as important factors modulating GPCR function in many cell types. In terms of melatonin signalling, RGS20 was shown to form a complex with MT1/G $\alpha_{i}$ [119], similarly RGS4 was shown to be involved in the desensitisation of MT1 in CHO cells [85] and recently described as a potential modulator of MT1 function in the PT [120]. Here again, RGS are amongst a non-exhaustive lists of candidate factors which roles need to be investigated within the PT.

\section{Acknowledgements}

The author would like to acknowledge Prof. Andrew Loudon, Dr. Perry Barrett and the reviewers for their insightful comments on the manuscript.

\section{References}

1 Goldman BD: Mammalian photoperiodic system: formal properties and neuroendocrine mechanisms of photoperiodic time measurement. J Biol Rhythms 2001;16:283301.

-2 Hazlerigg DG, Wagner GC: Seasonal photoperiodism in vertebrates: from coincidence to amplitude. Trends Endocrinol Metab 2006;17:83-91.

-3 Prendergast BJ, Gorman MR, Zucker I: Establishment and persistence of photoperiodic memory in hamsters. Proc Natl Acad Sci USA 2000;97:5586-5591.

-4 Paul MJ, Zucker I, Schwartz WJ: Tracking the seasons: the internal calendars of vertebrates. Philos Trans R Soc Lond B Biol Sci 2008;363:341-361.

- 5 Morgan PJ, Ross AW, Mercer JG, Barrett P: What can we learn from seasonal animals about the regulation of energy balance? Prog Brain Res 2006;153:325-337.

-6 Revel FG, Masson-Pevet M, Pevet P, Mikkelsen JD, Simonneaux V: Melatonin controls seasonal breeding by a network of hypothalamic targets. Neuroendocrinology 2009;90:1-14

7 Morgan PJ, Barrett P, Howell HE, Helliwell R: Melatonin receptors: localization, molecular pharmacology and physiological significance. Neurochem Int 1994;24:101-146.

$\checkmark 8$ Dardente H: Does a melatonin-dependent circadian oscillator in the pars tuberalis drive prolactin seasonal rhythmicity? J Neuroendocrinol 2007;19:657-666.
-9 Simonneaux V, Ribelayga C: Generation of the melatonin endocrine message in mammals: a review of the complex regulation of melatonin synthesis by norepinephrine, peptides, and other pineal transmitters. Pharmacol Rev 2003;55:325-395.

10 Prendergast BJ, Pyter LM: Photoperiod history differentially impacts reproduction and immune function in adult Siberian hamsters. J Biol Rhythms 2009;24:509-522.

11 Tricoire H, Locatelli A, Chemineau P, Malpaux B: Melatonin enters the cerebrospinal fluid through the pineal recess. Endocrinology 2002;143:84-90.

12 Hardeland R, Cardinali DP, Srinivasan V, Spence DW, Brown GM, Pandi-Perumal SR: Melatonin-A pleiotropic, orchestrating regulator molecule. Prog Neurobiol 2011;2010: 28.

13 Barrett P, Conway S, Morgan PJ: Digging deep - structure-function relationships in the melatonin receptor family. J Pineal Res 2003:35:221-230.

14 Reppert SM, Weaver DR, Cassone VM, Godson C, Kolakowski LF, Jr: Melatonin receptors are for the birds: molecular analysis of two receptor subtypes differentially expressed in chick brain. Neuron 1995;15:1003-1015 .

$\checkmark 15$ Dufourny L, Levasseur A, Migaud M, Callebaut I, Pontarotti P, Malpaux B, Monget P: GPR50 is the mammalian ortholog of Mellc: evidence of rapid evolution in mammals. BMC Evol Biol 2008;8:105.

-16 Morgan PJ, Ross AW, Mercer JG, Barrett P: Photoperiodic programming of body weight through the neuroendocrine hypothalamus. J Endocrinol 2003;177:27-34.
17 Lincoln GA: Melatonin entrainment of circannual rhythms. Chronobiol Int 2006;23: 301-306.

18 Hazlerigg DG, Morgan PJ, Messager S: Decoding photoperiodic time and melatonin in mammals: what can we learn from the pars tuberalis? J Biol Rhythms 2001;16:326-335.

19 Stoeckel ME, Porte A: Fine structure and development of the pars tuberalis in mammals; in Molta M-N PM (ed): Ultrastructure of Endocrine Cells and Tissues. Boston, Harvard Press, 1984, pp 29-39.

20 Stoeckel ME, Porte A, Hindelang-Gertner C, Dellmann HD: A light and electron microscopic study of the pre- and postnatal development and secretory differentiation of the pars tuberalis of the rat hypophysis. Z Zellforsch Mikrosk Anat 1973;142:347-365.

-21 Akimoto M, Nishimaki T, Arai Y, Uchinuma E, Yamauchi H, Kameda Y: Hes1 regulates formations of the hypophyseal pars tuberalis and the hypothalamus. Cell Tissue Res 2010; 340:509-521.

-22 Bockmann J, Bockers TM, Winter C, Wittkowski W, Winterhoff H, Deufel T, Kreutz MR: Thyrotropin expression in hypophyseal pars tuberalis-specific cells is 3,5,3'triiodothyronine, thyrotropin-releasing hormone, and pit-1 independent. Endocrinology 1997;138:1019-1028.

23 Sakai T, Sakamoto S, Ijima K, Matsubara K, Kato Y, Inoue K: Characterization of TSHpositive cells in foetal rat pars tuberalis that fail to express Pit-1 factor and thyroid hormone beta2 receptors. J Neuroendocrinol 1999;11:187-193. 
-24 Johnston JD, Klosen P, Barrett P, Hazlerigg DG: Regulation of MT melatonin receptor expression in the foetal rat pituitary. J Neuroendocrinol 2006;18:50-56.

-25 Guerra M, Blazquez JL, Peruzzo B, Pelaez B, Rodriguez S, Toranzo D, Pastor F, Rodriguez EM: Cell organization of the rat pars tuberalis: evidence for open communication between pars tuberalis cells, cerebrospinal fluid and tanycytes. Cell Tissue Res 2010;339: 359-381.

-26 Gross DS: The mammalian hypophysial pars tuberalis: a comparative immunocytochemical study. Gen Comp Endocrinol 1984;56: 283-298.

-27 Wittkowski W, Bockmann J, Kreutz MR, Bockers TM: Cell and molecular biology of the pars tuberalis of the pituitary. Int Rev Cytol 1999;185:157-194.

-28 Eagle RC, Tortonese DJ: Characterization and distribution of gonadotrophs in the pars distalis and pars tuberalis of the equine pituitary gland during the estrous cycle and seasonal anestrus. Biol Reprod 2000;63:826832 .

-29 Bockers TM, Bockmann J, Fauteck JD, Wittkowski W, Sabel BA, Kreutz MR: Evidence for gene transcription of adenohypophyseal hormones in the ovine pars tuberalis. Neuroendocrinology 1996;63:16-27.

$\checkmark 30$ Morgan PJ, Williams LM: The pars tuberalis of the pituitary: a gateway for neuroendocrine output. Rev Reprod 1996;1:153-161.

- 31 Klosen P, Bienvenu C, Demarteau O, Dardente $\mathrm{H}$, Guerrero $\mathrm{H}$, Pevet $\mathrm{P}$, Masson-Pevet $\mathrm{M}$ : The mt1 melatonin receptor and RORbeta receptor are co-localized in specific TSHimmunoreactive cells in the pars tuberalis of the rat pituitary. J Histochem Cytochem 2002;50:1647-1657.

-32 Dellmann HD, Stoeckel ME, Hindelang Gertner C, Porte A, Stutinsky F: A comparative ultrastructural study of the pars tuberalis of various mammals, the chicken and the newt. Cell Tissue Res 1974;148:313-329.

-33 Rutten A, Hewing M, Wittkowski W: Seasonal ultrastructural changes of the hypophyseal pars tuberalis in the hedgehog (Erinaceus europaeus L.). Acta Anat (Basel) 1988;133:217-223.

>34 Wittkowski W, Hewing M, Hoffmann K, Bergmann M, Fechner J: Influence of photoperiod on the ultrastructure of the hypophysial pars tuberalis of the Djungarian hamster, Phodopus sungorus. Cell Tissue Res 1984;238:213-216.

\35 Merks T, Schulze-Bonhage A, Wittkowski W: Photoperiod-dependent changes in exocytotic activity in the hypophyseal pars tuberalis of the Djungarian hamster, Phodopus sungorus. Cell Tissue Res 1993;273:287-291.

-36 Bockers TM, Niklowitz P, Bockmann J, Fauteck JD, Wittkowski W, Kreutz MR: Daily melatonin injections induce cytological changes in pars tuberalis-specific cells similar to short photoperiod. J Neuroendocrinol 1995;7:607-613.
37 Romera EP, Mohamed F, Fogal T, Dominguez S, Piezzi R, Scardapane L: Effect of the photoperiod and administration of melatonin on the pars tuberalis of viscacha (Lagostomus maximus maximus): an ultrastructural study. Anat Rec (Hoboken) 2010;293:871-878.

38 Wittkowski W, Bergmann M, Hoffmann K, Pera F: Photoperiod-dependent changes in TSH-like immunoreactivity of cells in the hypophysial pars tuberalis of the Djungarian hamster, Phodopus sungorus. Cell Tissue Res 1988;251:183-187.

39 Bergmann M, Wittkowski W, Hoffmann K: Ultrastructural localization of thyrotropin (TSH)-like immunoreactivity in specific secretory cells of the hypophyseal pars tuberalis in the Djungarian hamster, Phodopus sungorus. Cell Tissue Res 1989;256:649-652.

40 Bockmann J, Bockers TM, Vennemann B, Niklowitz P, Muller J, Wittkowski W, Sabel B, Kreutz MR: Short photoperiod-dependent down-regulation of thyrotropin-alpha and -beta in hamster pars tuberalis-specific cells is prevented by pinealectomy. Endocrinology 1996;137:1804-1813.

41 Arai Y, Kameda Y: Diurnal rhythms of common alpha-subunit mRNA expression in the pars tuberalis of hamsters and chickens. Cell Tissue Res 2004;317:279-288.

-42 Dardente H, Klosen P, Pevet P, Masson-Pevet M: MT1 melatonin receptor mRNA expressing cells in the pars tuberalis of the European hamster: effect of photoperiod. J Neuroendocrinol 2003;15:778-786.

43 Hanon EA, Routledge K, Dardente H, Masson-Pevet M, Morgan PJ, Hazlerigg DG: Effect of photoperiod on the thyroid-stimulating hormone neuroendocrine system in the European hamster (Cricetus cricetus). J Neuroendocrinol 2010;22:51-55.

44 Lincoln GA, Johnston JD, Andersson H, Wag ner G, Hazlerigg DG: Photorefractoriness in mammals: dissociating a seasonal timer from the circadian-based photoperiod response. Endocrinology 2005;146:3782-3790.

45 Yasuo S, Yoshimura T, Ebihara S, Korf HW: Photoperiodic control of TSH-beta expression in the mammalian pars tuberalis has different impacts on the induction and suppression of the hypothalamo-hypopysial gonadal axis. J Neuroendocrinol 2010;22:43-50.

46 von Gall C, Garabette ML, Kell CA, Frenzel S, Dehghani F, Schumm-Draeger PM, Weaver DR, Korf HW, Hastings MH, Stehle JH: Rhythmic gene expression in pituitary depends on heterologous sensitization by the neurohormone melatonin. Nat Neurosci 2002;5:234-238.

47 Johnston JD, Messager S, Ebling FJ, Williams LM, Barrett P, Hazlerigg DG: Gonadotrophin-releasing hormone drives melatonin receptor down-regulation in the developing pituitary gland. Proc Natl Acad Sci USA 2003;100:2831-2835.
48 Barrett P, MacLean A, Davidson G, Morgan PJ: Regulation of the Mel la melatonin receptor mRNA and protein levels in the ovine pars tuberalis: evidence for a cyclic adenosine $3^{\prime}, 5^{\prime}$-monophosphate-independent $\mathrm{Mel}$ la receptor coupling and an autoregulatory mechanism of expression. Mol Endocrinol 1996;10:892-902.

49 Helliwell RJ, Williams LM: The development of melatonin-binding sites in the ovine fetus. J Endocrinol 1994;142:475-484.

50 Goldman BD: 2003 Pattern of melatonin secretion mediates transfer of photoperiod information from mother to fetus in mammals. Sci STKE: 2003:PE29.

51 Beery AK, Paul MJ, Routman DM, Zucker I: Maternal photoperiodic history affects offspring development in Syrian hamsters. J Biol Rhythms 2008;23:445-455.

52 Shaw D, Goldman BD: Developmental changes in male Siberian hamsters (Phodopus sungorus) exposed to different gestational and postnatal photoperiods. J Pineal Res 2007;43:25-34.

53 Elliott JA, Goldman BD: Reception of photoperiodic information by fetal Siberian hamsters: role of the mother's pineal gland. J Exp Zool 1989;252:237-244.

54 Ansari N, Agathagelidis M, Lee C, Korf HW, von Gall C: Differential maturation of circadian rhythms in clock gene proteins in the suprachiasmatic nucleus and the pars tuberalis during mouse ontogeny. Eur J Neurosci 2009;29:477-489.

55 Prendergast BJ: MT1 melatonin receptors mediate somatic, behavioral, and reproductive neuroendocrine responses to photoperiod and melatonin in Siberian hamsters (Phodopus sungorus). Endocrinology 2010; 151:714-721.

56 Johnston JD: Photoperiodic regulation of prolactin secretion: changes in intra-pituitary signalling and lactotroph heterogeneity. J Endocrinol 2004;180:351-356.

57 Hodson DJ, Townsend J, Gregory SJ, Walters C, Tortonese DJ: Role of prolactin in the gonadotroph responsiveness to gonadotrophin-releasing hormone during the equine annual reproductive cycle. J Neuroendocrinol 2010;22:509-517.

58 Lincoln GA: Significance of seasonal cycles in prolactin secretion in male mammals; in Serio M (ed): Perspectives in Andrology. Serono Symposia. New York, Raven Press, 1989, vol 53, pp 299-306

59 Stirland JA, Johnston JD, Cagampang FR, Morgan PJ, Castro MG, White MR, Davis JR, Loudon AS: Photoperiodic regulation of prolactin gene expression in the Syrian hamster by a pars tuberalis-derived factor. J Neuroendocrinol 2001;13:147-157.

60 Lincoln GA, Clarke IJ: Photoperiodically-induced cycles in the secretion of prolactin in hypothalamo-pituitary disconnected rams: evidence for translation of the melatonin signal in the pituitary gland. J Neuroendocrinol 1994;6:251-260. 
61 Lincoln GA, Clarke IJ: Evidence that melatonin acts in the pituitary gland through a dopamine-independent mechanism to mediate effects of daylength on the secretion of prolactin in the ram. J Neuroendocrinol 1995;7: 637-643.

-62 Dupre SM, Loudon AS: Circannual clocks: annual timers unraveled in sheep. Curr Biol 2007;17:R216-R217.

63 Hazlerigg DG, Hastings MH, Morgan PJ: Production of a prolactin releasing factor by the ovine pars tuberalis. J Neuroendocrinol 1996;8:489-492.

64 Morgan PJ, Webster CA, Mercer JG, Ross AW, Hazlerigg DG, MacLean A, Barrett P: The ovine pars tuberalis secretes a factor(s) that regulates gene expression in both lactotropic and nonlactotropic pituitary cells. Endocrinology 1996;137:4018-4026.

65 Morgan PJ, Barrett P, Davidson G, Lawson W, Hazlerigg D: p72, a marker protein for melatonin action in ovine pars tuberalis cells: its regulation by protein kinase $\mathrm{A}$ and protein kinase $\mathrm{C}$ and differential secretion relative to prolactin. Neuroendocrinology 1994;59:325-335.

66 Morgan PJ: The pars tuberalis: the missing link in the photoperiodic regulation of prolactin secretion? J Neuroendocrinol 2000;12: 287-295.

67 Morgan PJ, Barrett P, Davidson G, Lawson W: Melatonin regualtes the synthesis and secretion of several proteins by pars tuberalis cells in the ovine pituitary J Neuroendocrinol 1992;4:557-563.

68 Graham ES, Webster CA, Hazlerigg DG, Morgan PJ: Evidence for the biosynthesis of a prolactin-releasing factor from the ovine pars tuberalis, which is distinct from thyrotropin-releasing hormone. J Neuroendocrinol 2002;14:945-954.

-69 Diaz Rodriguez E, Fernandez Alvarez C, Castrillon PO, Esquifino Parras AI, Diaz Lopez $B$ : In vitro pituitary prolactin, growth hormone and follicle stimulating hormone secretion during sexual maturation of female rats primed with melatonin. Acta Neurobiol Exp (Warsaw) 2001;61:27-33.

70 Badura LL, Goldman BD: Anterior pituitary release of prolactin is inhibited by exposure to short photoperiod. J Neuroendocrinol 1997;9:341-345.

-71 Blithe DL, Richards RG, Skarulis MC: Free alpha molecules from pregnancy stimulate secretion of prolactin from human decidual cells: a novel function for free alpha in pregnancy. Endocrinology 1991;129:2257-2259.

72 Chabot V, Gauthier C, Combarnous Y, Taragnat C: Stimulating effect of glycoprotein hormone free alpha-subunit and daily gonadotropin releasing hormone treatment on prolactin release from 50-day ovine foetal pituitary explants. J Neuroendocrinol 2001;13:199-208.
73 Guerra M, Rodriguez EM: Identification, cellular and subcellular distribution of 21 and $72 \mathrm{kDa}$ proteins (tuberalins?) secreted by specific cells of the pars tuberalis. J Endocrinol 2001;168:363-379.

74 Skinner DC, Lang AL, Pahl L, Wang Q: Substance P-immunoreactive cells in the ovine pars tuberalis. Neuroendocrinology 2009; 89:3-8.

75 Dupre SM, Miedzinska K, Duval CV, Yu L, Goodman RL, Lincoln GA, Davis JR, McNeilly AS, Burt DD, Loudon AS: Identification of Eya3 and TAC1 as long-day signals in the sheep pituitary. Curr Biol 2010;20:829835.

76 Yasuo S, Korf HW: The hypophysial pars tuberalis transduces photoperiodic signals via multiple pathways and messenger molecules. Gen Comp Endocrinol 2010.

77 Henderson HL, Hodson DJ, Gregory SJ, Townsend J, Tortonese DJ: Gonadotropinreleasing hormone stimulates prolactin release from lactotrophs in photoperiodic species through a gonadotropin-independent mechanism. Biol Reprod 2008;78:370-377.

78 Acosta M, Mohamed F: Effect of the photoperiod and administration of melatonin on folliculostellate cells of the pituitary pars distalis of adult male viscacha (Lagostomus maximus maximus). Acta Histochem 2010;8.

79 Ishikawa H, Nogami H, Shirasawa N: Novel clonal strains from adult rat anterior pituitary producing S-100 protein. Nature 1983; 303:711-713.

80 Hazlerigg DG, Morgan PJ, Lawson W, Hastings $\mathrm{MH}$ : Melatonin inhibits the activation of cyclic AMP-dependent protein kinase in cultured pars tuberalis cells from ovine pituitary. J Neuroendocrinol 1991;3:597-603.

81 von Gall C, Stehle JH, Weaver DR: Mammalian melatonin receptors: molecular biology and signal transduction. Cell Tissue Res 2002;309:151-162.

82 McNulty S, McNulty TJ, Schurov IL, Morgan PJ, Hastings MH: Melatonin-sensitive, serum-stimulated signalling in ovine pars tuberalis. J Pineal Res 1997;22:221-231.

83 Barrett P, Messager S, Schuster C, Moar KM, Mercer JG, Morgan PJ: Pituitary adenylate cyclase-activating polypeptide acts as a paracrine regulator of melatonin-responsive cells of the ovine pars tuberalis. Endocrinology 2002;143:2366-2375.

84 Barrett P, Schuster C, Mercer J, Morgan PJ: Sensitization: a mechanism for melatonin action in the pars tuberalis. J Neuroendocrinol 2003;15:415-421.

85 Witt-Enderby PA, Jarzynka MJ, Krawitt BJ, Melan MA: Knock-down of RGS4 and beta tubulin in $\mathrm{CHO}$ cells expressing the human MT1 melatonin receptor prevents melatonin-induced receptor desensitization. Life Sci 2004;75:2703-2715.
86 Hazlerigg DG, Gonzalez-Brito A, Lawson W, Hastings $\mathrm{MH}$, Morgan PJ: Prolonged exposure to melatonin leads to time-dependent sensitization of adenylate cyclase and downregulates melatonin receptors in pars tuberalis cells from ovine pituitary. Endocrinology 1993;132:285-292.

87 Barrett P, Choi WS, Morris M, Morgan P: A role for tyrosine phosphorylation in the regulation and sensitization of adenylate cyclase by melatonin. Faseb J 2000;14:1619-1628.

88 Sun ZS, Albrecht U, Zhuchenko O, Bailey J, Eichele G, Lee CC: RIGUI, a putative mammalian ortholog of the Drosophila period gene. Cell 1997;90:1003-1011.

89 Stehle JH, von Gall C, Korf HW: Melatonin: a clock-output, a clock-input. J Neuroendocrinol 2003;15:383-389.

-90 Ross AW, Morgan PJ: The pars tuberalis as a target of the central clock. Cell Tissue Res 2002;309:163-171

-91 Messager S, Hazlerigg DG, Mercer JG, Morgan PJ: Photoperiod differentially regulates the expression of Perl and ICER in the pars tuberalis and the suprachiasmatic nucleus of the Siberian hamster. Eur J Neurosci 2000; 12:2865-2870.

92 Carr AJ, Johnston JD, Semikhodskii AG, Nolan T, Cagampang FR, Stirland JA, Loudon AS: Photoperiod differentially regulates circadian oscillators in central and peripheral tissues of the Syrian hamster. Curr Biol 2003; 13:1543-1548.

-93 Lincoln G, Messager S, Andersson H, Hazlerigg D: Temporal expression of seven clock genes in the suprachiasmatic nucleus and the pars tuberalis of the sheep: evidence for an internal coincidence timer. Proc Natl Acad Sci USA 2002;99:13890-13895.

$\$ 94$ Lincoln GA, Andersson H, Loudon A: Clock genes in calendar cells as the basis of annual timekeeping in mammals - a unifying hypothesis. J Endocrinol 2003;179:1-13.

$\checkmark 95$ Messager S, Ross AW, Barrett P, Morgan PJ: Decoding photoperiodic time through Perl and ICER gene amplitude. Proc Natl Acad Sci USA 1999;96:9938-9943.

-96 Johnston JD, Ebling FJ, Hazlerigg DG: Photoperiod regulates multiple gene expression in the suprachiasmatic nuclei and pars tuberalis of the Siberian hamster (Phodopus sungorus). Eur J Neurosci 2005;21:2967-2974.

-97 Messager S, Garabette ML, Hastings MH, Hazlerigg DG: Tissue-specific abolition of Per1 expression in the pars tuberalis by pinealectomy in the Syrian hamster. Neuroreport 2001;12:579-582.

98 Dupre SM, Burt DW, Talbot R, Downing A, Mouzaki D, Waddington D, Malpaux B, Davis JR, Lincoln GA, Loudon AS: Identification of melatonin-regulated genes in the ovine pituitary pars tuberalis, a target site for seasonal hormone control. Endocrinology 2008;149:5527-5539. 
-99 Fustin JM, Dardente H, Wagner GC, Carter DA, Johnston JD, Lincoln GA, Hazlerigg DG: Egr1 involvement in evening gene regulation by melatonin. FASEB J 2009;23: $764-773$.

100 Unfried C, Burbach G, Korf HW, von Gall C: Melatonin receptor 1 -dependent gene expression in the mouse pars tuberalis as revealed by cDNA microarray analysis and in situ hybridization. J Pineal Res 2010;48: $148-156$.

-101 Hazlerigg DG, Andersson H, Johnston JD, Lincoln G: Molecular characterization of the long-day response in the Soay sheep, a seasonal mammal. Curr Biol 2004;14:334339.

-102 Dardente H, Wyse CA, Birnie MJ, Dupre SM, Loudon AS, Lincoln GA, Hazlerigg DG: A molecular switch for photoperiod responsiveness in mammals. Curr Biol 2010; 20:2193-2198.

103 Masumoto KH, Ukai-Tadenuma M, Kasukawa T, Nagano M, Uno KD, Tsujino K, Horikawa K, Shigeyoshi Y, Ueda HR: Acute induction of Eya3 by late-night light stimulation triggers TSHbeta expression in photoperiodism. Curr Biol 2010;20:2199-2206.

104 Hanon EA, Lincoln GA, Fustin JM, Dardente $\mathrm{H}$, Masson-Pevet M, Morgan PJ, Hazlerigg DG: Ancestral TSH mechanism signals summer in a photoperiodic mammal. Curr Biol 2008;18:1147-1152.

105 Hut RA: Photoperiodism: shall EYA compare thee to a summer's day? Curr Biol 2011; 21:R22-R25.

106 Jilg A, Moek J, Weaver DR, Korf HW, Stehle JH, von Gall C: Rhythms in clock proteins in the mouse pars tuberalis depend on MT1 melatonin receptor signalling. Eur J Neurosci 2005;22:2845-2854.
107 von Gall C, Weaver DR, Moek J, Jilg A, Stehle JH, Korf HW: Melatonin plays a crucial role in the regulation of rhythmic clock gene expression in the mouse pars tuberalis. Ann NY Acad Sci 2005;1040:508-511.

108 Gwinner E, Hau M, Heigl S: Melatonin generation and modulation of avian circadian rhythms. Brain Res Bull 1997;44:439444.

109 Foster RG, Follett BK, Lythgoe JN: Rhodopsin-like sensitivity of extra-retinal photoreceptors mediating the photoperiodic response in quail. Nature 1985;313:50-52.

110 Kuenzel WJ: The search for deep encephalic photoreceptors within the avian brain, using gonadal development as a primary in dicator. Poult Sci 1993;72:959-967.

111 Wyse C, Hazlerigg D: Seasonal biology: avian photoreception goes deep. Curr Biol 2009;19:R685-R687.

112 Nakane Y, Yoshimura T: Deep brain photoreceptors and a seasonal signal transduction cascade in birds. Cell Tissue Res 2010; 342:341-344

113 Yasuo S, Watanabe M, Okabayashi N, Ebihara S, Yoshimura T: Circadian clock genes and photoperiodism: comprehensive analysis of clock gene expression in the mediobasal hypothalamus, the suprachiasmatic nucleus, and the pineal gland of Japanese Quail under various light schedules. Endocrinology 2003;144:3742-3748.

114 Nakao N, Ono H, Yamamura T, Anraku T, Takagi T, Higashi K, Yasuo S, Katou Y, Kageyama S, Uno Y, Kasukawa T, Iigo M, Sharp PJ, Iwasawa A, Suzuki Y, Sugano S, Niimi T, Mizutani M, Namikawa T, Ebihara S, Ueda HR, Yoshimura T: Thyrotrophin in the pars tuberalis triggers photoperiodic response. Nature 2008;452:317-322.
115 Hazlerigg DG, Barrett P, Hastings MH, Morgan PJ: Are nuclear receptors involved in pituitary responsiveness to melatonin? Mol Cell Endocrinol 1996;123:53-59.

116 Dong C, Yuan L, Dai J, Lai L, Mao L, Xiang S, Rowan B, Hill SM: Melatonin inhibits mitogenic cross-talk between retinoic acidrelated orphan receptor alpha (RORalpha) and ERalpha in MCF-7 human breast cancer cells. Steroids 2010;75:944-951.

117 Jockers R, Maurice P, Boutin JA, Delagrange P: Melatonin receptors, heterodimerization, signal transduction and binding sites: what's new? Br J Pharmacol 2008; 154:1182-1195.

118 Coge F, Guenin SP, Fery I, Migaud M, Devavry S, Slugocki C, Legros C, Ouvry C, Cohen W, Renault N, Nosjean O, Malpaux B, Delagrange P, Boutin JA: The end of a myth: cloning and characterization of the ovine melatonin MT[2] receptor. Br J Pharmacol 2009; 158:1248-1262.

119 Maurice P, Daulat AM, Turecek R, Ivankova-Susankova K, Zamponi F, Kamal M, Clement N, Guillaume JL, Bettler B, Gales C, Delagrange P, Jockers R: Molecular organization and dynamics of the melatonin MT receptor/RGS20/G(i) protein complex reveal asymmetry of receptor dimers for RGS and G(i) coupling. EMBO J 2010;29: 3646-3659.

$>120$ Dupré SM, Dardente H, Birnie MJ, Loudon AS, Lincoln GA, Hazlerigg DG: Evidence for RGS4 modulation of melatonin and thyrotrophin signalling pathways in the pars tuberalis. J Neuroendocrinol 2011;23: 725-732. 